\title{
Studies on the Initiation of Protein Synthesis in Mouse Myeloma Tumors
}

\author{
GEORGE H. JONES
}

\author{
Department of Zoology, University of Michigan, Ann Arbor, Michigan 48104
}

Received February 18, 1975

\begin{abstract}
${ }^{35} \mathrm{~S}$ - and ${ }^{3} \mathrm{H}$-labeled short, nascent peptides have been extracted from mouse myeloma ribosomes after incubation of myeloma fragments with $\left[{ }^{35} \mathrm{~S}\right] \mathrm{methionine}$ and $\left[{ }^{3} \mathrm{H}\right] \mathrm{amino}$ acids. Edman analysis of these peptides reveals that most of the methionine is present at the $\mathrm{N}$ terminus but that other $\mathrm{N}$-terminal amino acids are also present. Light chains synthesized by the RPC-20 tumor fragments were purified from ribosomes, cell sap (released light chain) and the incubation medium (secreted light chain). Ribosomebound light chains were found to possess some $\mathrm{N}$-terminal methionine whereas released and secreted light chains did not. Since methionine is not the $\mathrm{N}$-terminal amino acid of light ( $\mathrm{L}$ ) chains purified from the urine of tumor-bearing mice, the results indicate that methionine initiates $L$ chain biosynthesis in the myeloma.

Total nascent ${ }^{35} \mathrm{~S}$-labeled peptides were extracted from myeloma ribosomes and fractionated on Sephadex G-50. Edman analysis of chromatographic fractions of varying sizes indicated that the percentage of $\mathrm{N}$-terminal methionine decreased with increasing chain length. This behavior is expected if methionine serves as an initiator amino acid but is removed before completion of the polypeptide chain on the ribosome.
\end{abstract}

Recent studies have indicated that methionine can serve as an initiator amino acid in eucaryotic protein synthesis. Thus, Jackson, and Hunter (1), using reticulocyte ribosomes synchronized at the point of initiation, have found that the amino-terminal amino acid of short, unfinished hemoglobin chains is methionine, whereas, the $\mathrm{N}$-terminal amino acid of longer and completed chains is valine. Similarly, Wilson and Dintzis have found that $15 \%$ of the labeled hemoglobin chains formed by reticulocytes have the $\mathrm{N}$-terminal sequence Met-Val (2). In vitro evidence in favor of initiation by methionine has been adduced by several laboratories. Housman et al. (3) have found that yeast methionyl-tRNA's can be fractionated into two species, one of which, when acylated, accepts a formyl group from formyl tetrahydrofolate and one of which does not. They have further shown, using an in vitro protein-synthesizing system from rabbit reticulocytes, that the formylatable species donates its methi- onine exclusively to the amino terminus of the hemoglobin chains made in this system, while the nonformylatable species supplies internal methionine. Smith and Marcker (4) and Brown and Smith (5) have obtained similar results using ribosomes and methionyl-tRNA's from ascites tumor cells, and similar functions for the methionyl-tRNA's have been demonstrated in other eucaryotic systems (6).

The initiator function of methionine thus seems well established, yet only a few specific eucaryotic proteins have been shown to be initiated with methionine. These include hemoglobin (7), protamines (8), and the viral proteins synthesized under the direction of the adenovirus genome (9). The present study was undertaken to determine whether methionine functions as an initiator amino acid in the mouse plasmacytoma and to further determine whether the specific immunoglobulin chains synthesized by plasmacytoma systems are initiated with methionine. Three 
plasma cell tumors were used in this study, RPC-20, a $\lambda$ chain producer, MOPC41 , a $\kappa$ chain producer and MOPC-104E, a heavy and light chain producer, the light chain of which is identical in structure to the $\lambda$ chain of RPC-20 $(10,11)$. It was of particular interest to investigate the initiation mechanism in tumors RPC-20 and MOPC-104E since the $L$ chain ${ }^{1}$ products of these tumors have been shown to possess amino-terminal L-pyroglutamic acid (10). pGlu has been suggested as an initiator amino acid in immunoglobulin biosynthesis (12).

While this manuscript was in preparation, Prasad and Peterkofsky presented evidence for the initiation of the RPC-20 light chain synthesis by methionine (13). The studies presented below confirm these results, extend them to the MOPC-41 and MOPC-104E tumors and also provide information regarding the possibility of initiation by other amino acids in the mouse plasma cell tumor.

\section{MATERIALS AND METHODS}

Plasma cell tumors were maintained in BALB/c mice. Fourteen- to twenty-one-day-old tumors were excised and finely minced with scissors in Hanks' solution. The fragments were washed in Hanks' solution and were incubated with $\left[{ }^{35} \mathrm{~S}\right]-$ or $\left[{ }^{3} \mathrm{H}\right]$ methionine and, in some experiments, also with a mixture of uniformly labeled $\left[{ }^{3} \mathrm{H}\right]$ - or ${ }^{14} \mathrm{C}$-labeled amino acids. All incubation mixtures contained the following components: Packed tumor fragments, 4 $\mathrm{ml}$; normal rabbit serum, $0.5 \mathrm{ml}$; [ $\left.{ }^{35} \mathrm{~S}\right]$ methionine, 10 $\mu \mathrm{Ci} / \mathrm{ml}$ (final concentration) or $\left[{ }^{3} \mathrm{H}\right]$ methionine, 25 $\mu \mathrm{Ci} / \mathrm{ml}$ (final concentration). [ $\left.{ }^{35} \mathrm{~S}\right]-$ and $\left[{ }^{3} \mathrm{H}\right]$ methionine incubation mixtures also contained the remaining 19 common amino acids (unlabeled) at a final concentration of $0.2 \mu \mathrm{mol} / \mathrm{ml}$. In incubations with $\left[{ }^{3} \mathrm{H}\right]$ - or ${ }^{14} \mathrm{C}$-amino acid mixtures, the label was added to give final concentrations of 25 or $5 \mu \mathrm{Ci} / \mathrm{ml}$, respectively, and those amino acids that were missing from the labeled mixtures were added (unlabeled) to a final concentration of $0.2 \mu \mathrm{mol} / \mathrm{ml}$ each. All reaction mixtures were brought to a final volume of $10 \mathrm{ml}$ with Hanks' solution, $\mathrm{pH} 7.4$, forti-

${ }^{1}$ Abbreviations used: DEAE, diethyl aminoethyl; L chain, light chain of immunoglobulin; pGlu, L-pyroglutamic acid; PTH, phenylthiohydantoin. fied with vitamins and a nitrogen source, and were preincubated for $5 \mathrm{~min}$ at $37^{\circ} \mathrm{C}$ without added label. The radioactive amino acids were then added and the incubations continued for the times indicated in the figure and table legends. The incorporation of amino acids was stopped by cooling the reaction mixtures and by the addition of cycloheximide to a final concentration of one $\mathrm{mg} / \mathrm{ml}$, followed by sedimentation of the tumor fragments.

The fragments were homogenized as described previously (14) in two volumes of Buffer $1(0.05 \mathrm{M}$ Tris-HCl, $\mathrm{pH} 7.6 ; 0.025 \mathrm{M} \mathrm{KCl} ; 0.005 \mathrm{M} \mathrm{MgCl}_{2}$ ), containing $1 \mathrm{mg} / \mathrm{ml}$ of cycloheximide and $1.2 \%$ Nonidet P-40 (Shell), and a postmitochondrial supernatant fraction was obtained by centrifugation of the homogenate at $5000 \mathrm{~g}$ for $10 \mathrm{~min}$ at $4^{\circ} \mathrm{C}$. The supernatant fluid was layered over a $5-\mathrm{ml}$ cushion of $2 \mathrm{M}$ sucrose in Buffer 1 containing $1 \mathrm{mg} / \mathrm{ml}$ of cycloheximide, and ribosomes were collected by centrifugation at $200,000 \mathrm{~g}$ for $18 \mathrm{~h}$ in an IEC A-321 rotor. The high speed supernatant fluid from this centrifugation was removed and saved, the sucrose cushion was discarded, and the ribosome pellets were rinsed and resuspended in Buffer 1 or $0.1 \mathrm{M}$ sodium acetate, pH 5.5.

Two methods were used to prepare peptidyl tRNA from the ribosomes. The first method employed was that described by Jackson and Hunter (1) and involves extraction of the ribosomes with phenol at $\mathrm{pH}$ 5.5. The second method was that of Slabaugh and Morris (15). Peptidyl tRNA solutions prepared by either method were deacylated by treatment with pancreatic ribonuclease and base (1). The solutions were then brought to $5 \%$ with formic acid, freed of insoluble material by centrifugation, and applied to a $1.5 \times 110-\mathrm{cm}$ column of Sephadex G-50 or a $1.2 \times$ 70-cm column of Sephadex G-10, each equilibrated with 5\% formic acid. Peptides were eluted with 5\% formic acid and relevant fractions were pooled and lyophilized. Edman degradation was preformed as described by Konigsberg and Hill (16).

${ }^{[35}$ S]methionine-labeled light chains were prepared by incubation of tumor fragments for $3-4 \mathrm{~h}$ in the medium described above and were purified as previously described (17). Sodium dodecyl sulfateacrylamide-gel electrophoresis was performed on $10 \%$ acrylamide gels as described by Laemmli (18). In some experiments gels were processed as previously described for scintillation counting (19). Electrophoresis of peptides was carried out in pyridine acetate, $\mathrm{pH} 1.9$, at $2500 \mathrm{~V}$ for $1-2 \mathrm{~h}$.

${ }^{35}$ S]methionine $(11-30 \quad \mathrm{Ci} / \mathrm{mmol}) \quad$ and $\left[{ }^{3} \mathrm{H}\right]$ methionine $(7.2 \mathrm{Ci} / \mathrm{mmol})$ were obtained from Amersham/Searle. Radioactive amino acid mixtures were purchased from New England Nuclear. Scintillation counting was performed as previously described (14). 
RESULTS

Methionine is Found at the N-Terminal Position of Nascent Polypeptide Chains Obtained from Mouse Myeloma Ribosomes

Following the procedure of Jackson and Hunter (1), short, nascent, $\left[{ }^{35}\right.$ S $]$ methionine-labeled peptides were prepared by phenol extraction of ribosomes labeled and purified as described in Materials and Methods. Approximately 10\% of the total ribosome-bound ${ }^{35} \mathrm{~S}$-peptides were extracted by this procedure. The peptide material in the aqueous phase from such an extraction was subjected to Sephadex G-50 chromatography, and a single radioactive peak was obtained (data not shown). The leading and trailing halves of this peak were pooled separately, concentrated and subjected to paper electrophoresis with methionine as a reference. None of the peptide fractions (from any of the three tumors tested) contained free methionine (data not shown). Table I shows the results of Edman degradation of the leading half (fraction A) and trailing half (fraction B) from the three tumors. It can be seen that $70-85 \%$ of the methionione in fractions $A$ and $B$ from each tumor was released in the first round of Edman degradation. Since the efficiency of the Edman reaction is generally $75-85 \%$ for peptides (16), it can be concluded that nearly all methionine in fractions $A$ and $B$ is amino terminal. The high level of $\mathrm{N}$ - terminal methionine found on these small, nascent myeloma peptides suggests that methionine is the initiator amino acid for the synthesis of at least some myeloma proteins. These data support the results obtained in vitro by Jones and Mach with methionyl-tRNA's (20).

Specific information on the molecular sizes of peptides A and B was obtained by chromatography of the phenol-extracted aqueous phases on Sephadex G-10. It was found that the ${ }^{35} \mathrm{~S}$ label of peaks $A$ and $B$ eluted in a major peak with a mobility slightly greater than that of reduced glutathione. Skewing toward smaller sizes was also observed (data not shown). Thus, phenol-extraction procedures appear to yield tRNA molecules bearing di- to tetrapeptides.

\section{Is Methionine the Only Initiator Amino} Acid Used in Myeloma Protein Synthesis?

To determine whether all proteins in mouse myelomas are initiated with methionine, it was necessary to establish that nascent peptides from myeloma ribosomes contained only methionine as their N-terminal amino acid. To this end, doubly labeled incubations were performed with MOPC-41 and RPC-20 tumor fragments. For these experiments, combinations of $\left[{ }^{35} \mathrm{~S}\right]$ methionione and an $\left[{ }^{3} \mathrm{H}\right]$ amino acid mixture or $\left[{ }^{3} \mathrm{H}\right]$ methionine and a ${ }^{14}[\mathrm{C}-]$ amino acid mixture were used. Short, nascent peptides were prepared by phenol extraction of labeled ribosomes, and peaks A

TABLE I

Emman Analysis of $\left[{ }^{35}\right.$ S]Methionine-Labeled Peptides Isolated by Phenol Extraction ${ }^{a}$

\begin{tabular}{|c|c|c|c|c|c|c|c|c|c|}
\hline \multirow{2}{*}{$\begin{array}{c}\text { G-50 } \\
\text { peak }\end{array}$} & \multicolumn{3}{|c|}{ Initial cpm } & \multicolumn{3}{|c|}{ CPM in ethyl acetate } & \multicolumn{3}{|c|}{ Percent N-terminal } \\
\hline & MOPC-4 & RPC-20 & MOPC-104E & MOPC-4 & RPC-20 & MOPC-104E & MOPC-4 & $\mathrm{RPC}-20$ & PC-104E \\
\hline A & 3920 & 3080 & 2320 & 3290 & 2150 & 2040 & 84.0 & 70.0 & 72.3 \\
\hline $\mathbf{B}$ & 4040 & 3280 & 3400 & 3290 & 2450 & 2952 & 81.5 & 74.6 & 86.8 \\
\hline
\end{tabular}

a Plasmacytoma ribosomes were prepared from $\left[{ }^{35} \mathrm{~S}\right]$ methionine incubations as described in Materials and Methods and the legend to Fig. 1. The ribosomes were extracted with phenol at $\mathrm{pH} 5.5$ and the aqueous extracts were deacylated and chromatographed on Sephadex G-50 as described in Fig. 1. The leading (A) and trailing (B) halves of the peptide peak were pooled, concentrated and subjected to Edman degradation (15). After cyclization in trifluoroacetic acid, the phenylthiohydantoins were extracted into ethyl acetate. Aliquots of the ethyl acetate extracts were counted in a toluene-Omnifluor scintillant. Ethyl acetateextractable ${ }^{35} \mathrm{~S}$ counts were shown by paper chromatography to be present in PTH-methionine. 
and B from Sephadex G-50 columns were collected together. As a control for this experiment, the high speed supernatant fraction (S200, presumably containing released polypeptide chains which were expected to possess little, if any, $\mathrm{N}$-terminal methionine) from the ribosome pelleting was also prepared. The S200's were subjected to Edman degradation along with the nascent peptides from the corresponding incubations. The results of these experiments are shown in Table II. It can be seen that $70-85 \%$ of the $\left[{ }^{35}\right.$ S]methionine was released after one round of Edman degradation. Surprisingly, it was observed that $15-25 \%$ of the tritium counts (amino acids other than methionine) were also released in the first round for all the tumors tested. This result was also obtained with peptides from tumor fragments labeled singly with methionine or amino acids. These data indicate that methionine is not the only $\mathrm{N}$-terminal amino acid on short, nascent myeloma peptides and suggest that (i)initiating methionione is removed very rapidly from most nascent polypeptides, before they reach lengths of greater than four to five amino acids; or (ii)amino acids other than methionine participate in initiation in the myeloma. Low percentages of $\mathrm{N}$-terminal methionine and of other amino acids were observed on Edman analysis of the soluble proteins obtained in the S200 fractions (Table II). The biological significance of these latter results is not clear, but the values obtained are similar to those observed on Edman analysis of those nascent myeloma peptides that are excluded from Sephadex G-50 (Table III).

\section{Methionine Is the Initiator Amino Acid for Myeloma Immunoglobulin Light Chain Biosynthesis}

In view of the data presented above, it did not seem possible to demonstrate methionine initiation of light chain biosynthesis by direct Edman analysis of myeloma peptides. It was, thus, necessary to attempt the purification of the light chains synthesized by tumor fragments under the conditions described above. To this end, RPC-20 fragments were incubated with $\left[{ }^{35} \mathrm{~S}\right]$ methionine for $30 \mathrm{~min}$ or $3 \mathrm{~h}$. Total nascent peptides were isolated from the ribosomes by the procedure of Slabaugh and Morris (15) after the 30-min incubation. The cell sap (S200) and incubation medium from the 3-h incubation were prepared and processed as described in Materials and Methods. Labeled light chain was purified from the S200 and cell-free incubation medium by chromatography on DEAE-cellulose (17). Labeled light chain protein was isolated from labeled ribosomes by DEAE-cellulose and Sephadex G-200 chromatography. Dodecyl sulfate-

\section{TABLE II}

Edman Analysis of Sephadex G-50 Peaks A and B and S200's from Doubly labeled Incubations of Plasmacytoma Fragments ${ }^{a}$

\begin{tabular}{|c|c|c|c|c|c|c|}
\hline \multirow[t]{2}{*}{ Sample } & \multicolumn{2}{|c|}{ Initial $\mathrm{cpm} \times 10^{-3}$} & \multicolumn{2}{|c|}{$\begin{array}{l}\text { Cpm } \times 10^{-3} \text { in } \\
\text { ethyl acetate }\end{array}$} & \multicolumn{2}{|c|}{ Percent N-terminal } \\
\hline & ${ }^{35} \mathrm{~S}$ & ${ }^{3} \mathrm{H}$ & ${ }^{35} \mathrm{~S}$ & ${ }^{3} \mathbf{H}$ & ${ }^{35} \mathrm{~S}$ & ${ }^{3} \mathbf{H}$ \\
\hline RPC-20 AB & 3.50 & 7.91 & 2.60 & 1.85 & 74.2 & 23.4 \\
\hline RPC-20 S200 & 321 & 976 & 0.52 & 8.14 & 0.2 & 0.8 \\
\hline MOPC-41 AB & 2.20 & 5.60 & 1.83 & 0.84 & 83.1 & 15.0 \\
\hline MOPC-41 S200 & 465 & 1180 & 3.44 & 7.54 & 0.7 & 0.6 \\
\hline
\end{tabular}

${ }^{a}$ Plasmacytoma fragments were incubated with radioactive amino acids as described in Materials and Methods, and ribosomes were extracted with phenol to prepare nascent peptides. The high speed supernatant fraction resulting from the preparation of the labeled ribosomes was treated for $2 \mathrm{~h}$ at $37^{\circ} \mathrm{C}$ and $\mathrm{pH} 10$ and freed of amino acids by passage through Sephadex G-25. Edman analysis was performed on the combined A and B peptide fractions and on a suitable aliquot of the high speed supernatant fraction. Results essentially identical to those presented above were obtained in the incubations containing $\left[{ }^{3} \mathrm{H}\right]$ methionine and ${ }^{14} \mathrm{C}$-labeled amino acids. 
TABLE III

Results of Edman Analysis of [ ${ }^{35}$ S]Methionine-Labeled Peptides from Plasmacytoma PePtidyl $\operatorname{tRNA}^{a}$

\begin{tabular}{|c|c|c|c|c|c|c|c|c|c|}
\hline \multirow{2}{*}{$\begin{array}{l}\text { G-50 } \\
\text { peak }\end{array}$} & \multicolumn{3}{|c|}{ Initial cpm } & \multicolumn{3}{|c|}{ Cpm in ethyl acetate } & \multicolumn{3}{|c|}{ Percent N-terminal } \\
\hline & RPC-20 & MOPC-41 & $\begin{array}{r}\text { MOPC- } \\
104 \mathrm{E}\end{array}$ & RPC-20 & MOPC-41 & $\begin{array}{l}\text { OPC- } \\
104 E\end{array}$ & RPC-20 & MOPC-41 & $\begin{array}{l}\text { PPC. } \\
104 E\end{array}$ \\
\hline $\mathbf{I}$ & 19,800 & 21,600 & 8,650 & 158 & 234 & 130 & 0.8 & 1.1 & 1.5 \\
\hline II & 14,400 & 41,400 & 6,800 & 820 & 1,610 & 230 & 5.7 & 3.9 & 3.4 \\
\hline III & 2,450 & 6,150 & 1,430 & 415 & 855 & 177 & 16.9 & 13.9 & 12.3 \\
\hline IV & 1,050 & 1,410 & 880 & 345 & 550 & 410 & 32.8 & 39.0 & 46.5 \\
\hline V & 1,800 & 1,350 & 680 & 905 & 650 & 350 & 50.2 & 48.1 & 51.5 \\
\hline
\end{tabular}

${ }^{a}$ Fractions from the Sephadex G-50 column were pooled as described in Fig. 3 and concentrated by lyophilization. Aliquots of each peak were subjected to Edman degradation as described by Konigsberg and Hill (16).

acrylamide-gel electrophoresis of the appropriate fractions from these columns indicated that the major radioactive protein in each case had a mobility similar to authentic light chain and contained at least $90 \%$ of the total radioactivity recovered from the gels (data not shown).

The light chains obtained by this procedure were subjected to Edman degradation with the result that $8.14,0.65$ and $0.23 \%$, respectively, of the total incorporated methionine was $\mathrm{N}$-terminal on ribosomebound, released and secreted light chains. These data suggest that at least some ribosome-bound RPC-20 light chains possess $\mathrm{N}$-terminal methionine, whereas released and secreted chains do not. This result was confirmed by the chromatograhic analysis of the ethyl acetate extracts following Edman degradation. Only the extract from the analysis of ribosome-bound $\mathrm{L}$ chain contained PTH-methionine (Fig. 1). Since methionine is not the amino-terminal amino acid of the RPC-20 light chains isolated from urine or serum (10), initiating methionine must be removed from most $\mathrm{L}$ chains before they are completed. Additional evidence in support of this contention is presented below.

Initiating Methionine is Lost from the Growing Polypeptide Chains Before Their Completion

The data presented above and in Table II indicate that released and secreted myeloma peptide chains contain little, if any $\mathrm{N}$-terminal methionine. It was of interest to determine whether the $\mathrm{N}$-terminal methionine found on short, nascent peptide chains was lost after chain completion or at some step during chain growth. For this purpose, labeled nascent chains were used for the preparation of peptidyl tRNA by the procedure of Slabaugh and Morris (15). Figure 2 depicts the profile of radioactivity obtained on chromatography of the RPC20 peptidyl tRNA on DEAE-cellulose. In general, 45-60\% of the applied radioactivity was recovered in peak I from the DEAE-cellulose column and $25-35 \%$ was recovered in peak II. The materal eluting in peak I was shown by chromatography on Sephadex G-50 to consist mainly of peptides that were excluded from the Sephadex column. Whether this material represents peptides obtained from peptidyl tRNA by deacylation or large peptides that stick nonspecifically to the ribosome has not been determined. The material in peak II is peptidyl tRNA (15).

Peptides obtained by deacylation of peak II from the DEAE-cellulose column were separated by gel filtration. The profile of such a column is shown in Fig. 3 for RPC20 peptides. Similar profiles were obtained for MOPC-41 and MOPC-104E peptides. Peptides of sizes ranging from 1 or 2 to more than 100 amino acids were obtained, with the recovery of radioactivity increasing with increasing peptide chain length. Fractions were pooled as indicated in Fig. 3 and subjected to Edman degradation. The results of typical $\mathrm{N}$-terminal analyses are shown in Table III for all three tumors 


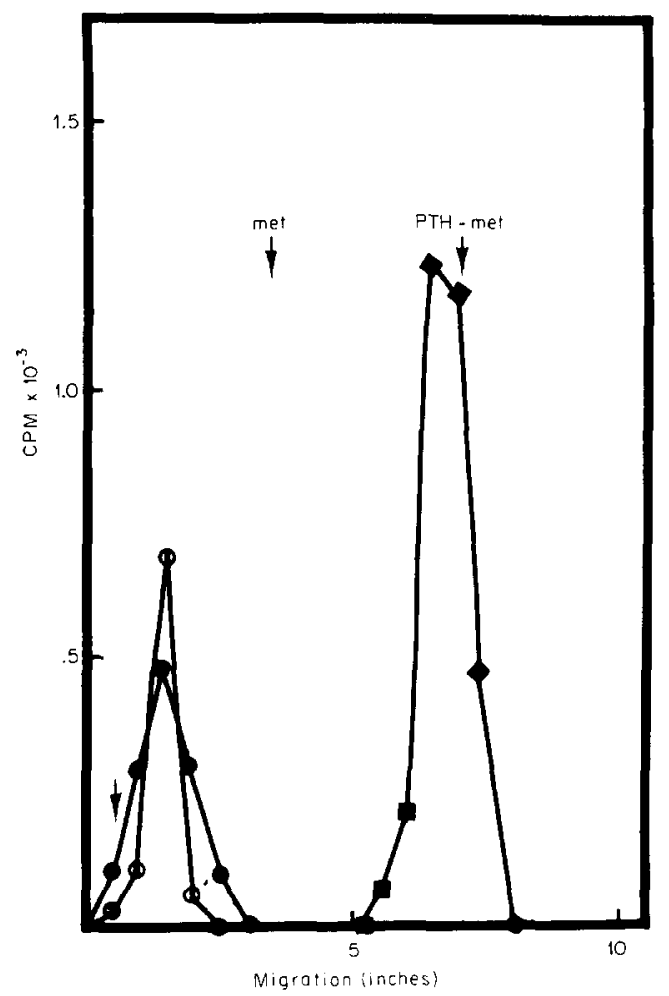

Fig. 1. Paper chromatography of the ethyl acetate-extractable products obtained by Edman degradation of RPC-20 light chains. Each of the light chain fractions described in the text was subjected to Edman degradation and the ethyl acetate extractable radioactivity was analyzed by ascending paper chromatography on Whatman \#1 filter paper using butanol/acetic acid/water $(4: 1: 5$, by volume) as the solvent. Authentic PTH-methionine was used as a standard. Open circles, light chain from cell sap; closed circles, light chain from incubation medium; squares, ribosome-bound light chain.

tested. As one would predict if methionine acts as an initiator amino acid in this system, the percentage of the total methionine in each column cut which was present as $\mathrm{N}$-terminal methionine increased from about $1 \%$ in fraction I (greater than 100 amino acids) to about $50 \%$ in fraction $\mathrm{V}$ (less than 15 amino acids).

\section{DISCUSSION}

The data presented above may be summarized as follows: (i)Methionine is present at the $N$ terminus of short, nascent peptides synthesized on mouse plasmacytoma ribosomes; (ii)most methionine in these peptides is $\mathrm{N}$ terminal, but methionine is not the only $\mathrm{N}$-terminal amino acid present; (iii)light chains purified from RPC20 ribosomes possess N-terminal methionine whereas light chains from the cell sap and secreted light chains do not; (iv)the percentage of $\mathrm{N}$-terminal methionine present on nascent myeloma peptides decreases with increasing peptide chain length. Although a maximum of only $50 \%$

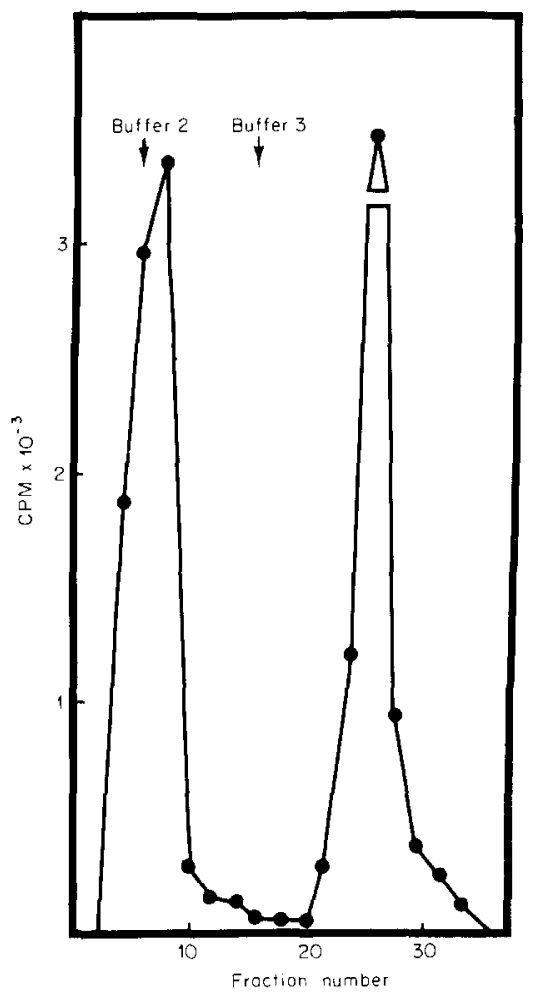

FIg. 2. Preparation of peptidyl tRNA by DEAEcellulose chromatography. Peptidyl tRNA was obtained from $\left.{ }^{35} \mathrm{~S}\right]$ methionine-labeled ribosomes by the procedure of Slabaugh and Morris (15). Fourmilliliter fractions were collected initially from the DEAE-cellulose column, washed with Buffer 2 (8 M urea, $0.05 \mathrm{M}$ 2-mercaptoethanol, and $0.1 \mathrm{M}$ sodium acetate, $\mathrm{pH} \mathrm{5.5)}$ at a flow rate of one $\mathrm{ml} / \mathrm{min}$. At fraction 15 , the buffer was changed and 2-ml fractions were collected by elution with Buffer $3(8 \mathrm{M}$ urea, $0.05 \mathrm{M}$ 2-mercaptoethanol, $0.75 \mathrm{M}$ sodium acetate, pH 5.5). Fifty-microliter aliquots of fractions 1-14 were counted and $250-\mathrm{ml}$ aliquots were counted from fractions 15-40. Fractions 3-10 and 22-31 were pooled and denoted DEAE peaks I and II, respectively. Similar patterns were obtained for peptide preparations from tumors MOPC-41 and MOPC. 104E (not shown) and RPC-20 (shown). 


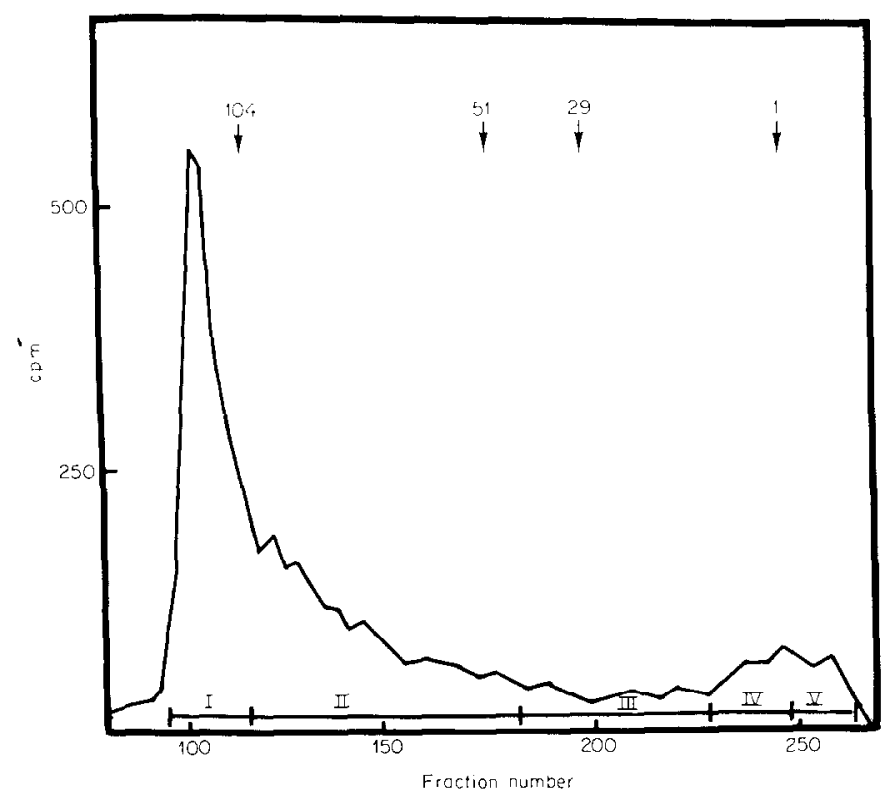

Frg. 3. Fractionation of nascent peptides from RPC-20 peptidyl tRNA on Sephadex G-50. DEAE peak II (Fig. 2) was deacylated and the released peptides were chromatographed on Sephadex G-50 as described in Materials and Methods. Cytochrome (104 amino acids), insulin (51 amino acids), glucagon ( 29 amino acids) and free methionine were used as molecular weight markers. Fractions were pooled as indicated.

$\mathrm{N}$-terminal methionine was obtained for the smallest peptide fraction isolated by Sephadex G-50 chromatography of total peptides (fraction V of Fig. 3), it should be noted that this fraction contained a large amount of urea remaining from the DEAE-cellulose chromatographic step. In control experiments, it was generally observed that urea interfered with the Edman analysis, yielding lower than actual $\mathrm{N}$-terminal values. Thus, it is possible that nearly all the methionine in the fraction $\mathrm{V}$ peptides is $\mathrm{N}$ terminal.

The results presented above provide strong evidence for the function of methionine as an initiator of protein sythesis generally in the plasma cell tumor and also indicate that methionine specifically initiates the biosynthesis of the RPC-20 immunoglobulin chain. This latter result has also been obtained by Prasad and Peterkofsky (13). The dita presented in the latter publication and in the present report are consistent with the finding that the RPC20 light chain purified from urine possesses $\mathrm{N}$-terminal pGlu. $\mathrm{N}$-terminal methionine is removed from the immunoglobu- lin chains before their secretion by the cells. These observations would seem to eliminate the possibility that pGlu serves to initiate $\mathrm{L}$ chain synthesis in tumor RPC-20.

Another observation that argues for the function of methionine as an initiator amino acid in the plasmacytoma system is the observed decrease in $\mathrm{N}$-terminal methionine content with increasing peptide chain length. If one assumes that the larger and smaller nascent peptides represent the same finished polypeptides, then the reduction in $\mathrm{N}$-terminal methionine represents either removal of $\mathrm{N}$-terminal methionine or a relative increase in internal methionine or both. Since the RPC-20, MOPC-41 and MOPC-104E light chains contain only two internal methionines (10, 11 ), it seems very unlikely that a relative increase in internal methionine can be wholly responsible for the decrease in $\mathrm{N}$ terminal methionine with increasing chain length which was observed in the experiments of Table II.

Recent studies with purified L chain mRNA indicate that the chains are ini- 
tially synthesized as higher molecular weight precursors $(21,22)$. Indeed it has been shown that methionine initiaties the synthesis of the precursor in reticulocyte lysates primed with myeloma mRNA (21). It seems likely that the labeled product purified from ribosomes in the present studies contains a significant proportion of the precursor, since the light chain derived therefrom should not possess $\mathrm{N}$-terminal methionine (10). Although ribosomebound protein was analyzed by acrylamide-gel electrophoresis with an $\mathrm{L}$ chain standard, it is unlikely that the electrophoretic procedure used would have allowed the separation of the precursor from the final $\mathrm{L}$ chain. The data do suggest that small amounts of precursor accumulate inside the myeloma cells.

\section{ACKNOWLEDGMENTS}

This research was supported by Grant No. 5ROlCA 12752 from the National Cancer Institute, U. S. Public Health Service. The author expresses gratitude to Dr. Bernard Mach and Dr. Pierre Vassalli in whose laboratories many of the techniques described herein were developed.

\section{REFERENCES}

1. JACkson, R., ANd Hunter, T. (1970) Nature (London) 227, 672-676.

2. Wilson, D. B., And Dintzis, H. M. (1970) Proc. Nat. Acad. Sci. USA 66, 1282-1289.

3. Housman, D., Jacobs-Lorena, M., RaJBhanDARY, U. L., AND Lodish, H. F. (1970) Nature (London) 227, 913-918.

4. Smith, A. E., and Marcker, K. A. (1970) Na- ture (London) 226, 607-610.

5. Brown, J. C., ANd Smith, A. E. (1970) Nature (London) 226, 610-612.

6. LuCAS-LenaRd, J., AND LipMaNN, F. (1971) Annu. Rev. Biochem. 40, 409-448.

7. Hunter, A. R., ANd JaCkson, R. J. (1971) Eur. J. Biochem. 19, 313-322.

8. Wigle, D. T., and Dixon, G. H. (1970) Nature (London) 227, 676-680.

9. Caffier, H., Raskas, H. J., Parsons, J. T., and Green, M. (1971) Nature New Biol. 229, 239241.

10. Apella, E. (1971) Proc. Nat. Acad. Sci. USA 68, 590-594.

11. Gray, W. R., Dreyer, W. J., and Hood, L. (1967) Science 155, 465-467.

12. Rush, E. A., AND Stark, J. L. (1970) Biochim. Biophys. Acta 199, 41-55.

13. Prasad, C., and Peterkofsky, A. (1975) J. Biol. Chem. 250, 171-174.

14. Bridges, K. R., AND JonEs, G. H.(1973) Biochemistry 12, 1208-1212.

15. Slabaugh, R. C., and Morris, A. J. (1970) J. Biol Chem. 245, 6182-6189.

16. Konigsberg, W., AND Hill, R. J. (1962) J. Biol. Chem. 237, 2547-2561.

17. Potter, M. (1967) Methods Cancer Res. 2, 105157.

18. LaEmmLI, U. K. (1970) Nature (London) 227, 680-685.

19. Jones, G. H. (1973) Biochem. Biophys. Res. Commun. 51, 88-93.

20. Jones, G. H., ANd Mach, B. (1973) Biochim. Biophys. Acta 312, 399-402.

21. Milstein, C., Brownlee, C. G., Harrison, T. M., and Mathews, M. B. (1972) Nature New Biol. 239, 117-120.

22. Mach, B., Faust, C., and Vassalli, P. (1973) Proc. Nat. Acad. Sci. USA 70, 451-455. 